\title{
Nueva alternativa para evitar la retirada del catéter de Hemodiálisis. Caso clínico
}

\author{
Isabel Crehuet Rodríguez ${ }^{1}$, Marta Ramírez Crehuet ${ }^{1}$, María Albina Bernárdez Lemus ${ }^{1}$, Beatriz Toribio Manrique ${ }^{1}$, \\ Belén Gómez Giralda² \\ ${ }^{1}$ Unidad de diálisis. Hospital Universitario Rio Hortega. Valladolid. España \\ ${ }^{2}$ Facultativo Especialista de Área. Unidad de diálisis. Hospital Universitario Río Hortega. Valladolid. España
}

\section{Resumen}

Una de las mayores complicaciones de la utilización de los catéteres venosos tunelizados para hemodiálisis son las infecciones, de las cuales las "tunelitis" o infección del túnel subcutáneo, en general, conllevan la retirada del catéter.

Presentamos en el siguiente caso a una paciente de 81 años, pluripatológica y graves problemas de accesos vasculares en la que produjo una infección recurrente del túnel subcutáneo del catéter (tunelitis). Para evitar recambiar ese catéter, dado su buen funcionamiento y la enorme dificultad para conseguir un nuevo acceso vascular, se aplicó un tratamiento específico consistente en instilar en el túnel subcutáneo 500 mg de Vancomicina disuelta en suero salino mediante un Abbocath ${ }^{\circledR} n^{\circ} 26$, con el fin de impregnar los componentes del catéter. Un año después de este episodio el catéter se mantuvo funcionante sin signos de infección.

PALABRAS CLAVE: bacteriemia relacionada con catéter; catéter tunelizado; hemodiálisis; infección.

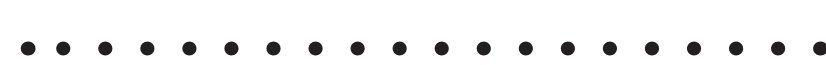

\section{New alternative to prevent removal of the hemodialysis catheter. Case report.}

\begin{abstract}
One of the major complications of the use of tunnelled venous catheters for hemodialysis are infections, of which "tunnelitis" or subcutaneous tunnel infection and generally involve the removal of the catheter.
\end{abstract}

The case of an 81-year-old patient with multiple pathologies and severe vascular access problems in which she developed a recurrent subcutaneous tunnel tunnel infection (tunelitis) is presented. In order to avoid exchanging that catheter, due to its good functioning and the enormous difficulty to achieve a new vascular access, a specific treatment was applied consisting of instilling in the subcutaneous tunnel $500 \mathrm{mg}$ Vancomycin dissolved in saline by means of an Abbocath ${ }^{\circledast} n^{0} 26$, in order to impregnate the components of the catheter. A year after this episode the catheter remained functioning without signs of infection.

KEYWORDS: bacteremia related to the catheter; tunneled catheter; hemodialysis; infection.

\section{Introducción}

Todas las Guías de Acceso Vascular para hemodiálisis (HD) recomiendan la utilización de la fístula arterio-venosa (FAV) nativa por encima de cualquier otra opción ${ }^{1}$. Sin embargo, cada vez es mayor el número de catéteres venosos centrales tunelizados (CVCT) empleados para realizar esta terapia. La avanzada edad de muchos pacientes incidentes en HD, la mayor prevalencia de diabetes mellitus y de comorbilidad cardiovascular asociada, hace que frecuentemente esté contraindica- 
do realizar una FAV. La utilización de CVCT no está exenta de riesgos y las bacteriemias relacionadas con el catéter (BRC) son unas complicaciones frecuentes y graves, siendo la segunda causa de muerte en estos pacientes. El riesgo de que se produzca una infección es entre 7 y 20 veces superior si se utiliza un catéter en lugar de una $\mathrm{FAV}^{2}$.

Las vías por las que los gérmenes pueden penetrar en el organismo y provocar una infección suelen ser la colonización endoluminal producida a través de las conexiones externas por manipulación, que acostumbra ser la más frecuente; la extraluminal, a través del orificio de salida del catéter (OSC) y, excepcionalmente, por diseminación hematógena desde otro foco de infección ${ }^{3}$.

Cuando los gérmenes penetran a través del OSC, van migrando a lo largo del túnel originando una infección localizada del mismo (tunelitis), que se manifiesta con un eritema a lo largo de todo el trayecto subcutáneo del catéter, dolor, edema, secreción purulenta, etc. Esta infección puede generalizarse y originar una bacteriemia ${ }^{4,5}$.

Las guías de acceso vascular recomiendan la retirada del catéter cuando hay una infección del túnel ${ }^{1}$, pues además de originar una infección sistémica pueden provocar un desgaste del anclaje o manguito de dacron (cuff), con el riesgo de la pérdida espontánea del catéter' ${ }^{6}$.

Analizamos el caso de una paciente con infecciones recurrentes del túnel subcutáneo del catéter a la que se prescribió un tratamiento innovador.

\section{Presentación del caso}

Mujer de 81 años, con múltiples patologías: hipertensión arterial, artrosis, arritmias controladas con marcapasos en lado izquierdo. En 2008 en seguimiento en consulta de enfermedad renal crónica avanzada, presentaba enfermedad renal crónica, estadio 5, por probable nefroangioesclerosis. Para iniciar programa de hemodiálisis se realizaron dos FAVs nativas que fracasaron; ante las dificultades que planeaba realizar una nueva intervención y teniendo en cuenta su estado clínico se informó a la paciente de su situación, optando ella por un tratamiento conservador que no incluyera terapia sustitutiva.

- En abril de 2015, acudió a urgencias con un diagnóstico de insuficiencia cardiaca descompensada y derrame pleural severo. Se realizó una sesión de HD con catéter temporal en vena femoral derecha. Una vez solventada esta situación, la paciente y la familia se plantearon de nuevo la posibilidad de tratamiento renal sustitutivo, por lo que se colocó un CVCT en vena yugular derecha, ingresando en el programa de HD crónica.

- En julio del mismo año se recambió este catéter por mal funcionamiento. Un mes después persistía la disfunción, se descartó una trombosis en la vena cava superior y se volvió a recambiar sin éxito persistiendo el mal funcionamiento, por lo que un mes más tarde se llevó a cabo un cuarto intento sin éxito aunque radiológicamente se comprobó que estaba bien colocado. No obstante, ante las pocas opciones para realizar un nuevo acceso se decidió mantenerlo y colocar otro catéter en vena femoral izquierda. Se mantuvieron ambos catéteres un tiempo para evaluar cuál funcionaba mejor y finalmente se retiró el catéter femoral, manteniéndose el inicial en la vena yugular derecha.

- En septiembre del mismo año presentó una BRC por un Staphylococcus aureus meticilin-sensible (SAMS) con foco en el catéter. Se inició tratamiento empírico vía sistémica con Linezolid y Ciprofloxacino, con una evolución favorable.

- En noviembre presentó una nueva BCR por SAMS con foco en el catéter, con sintomatología evidente de infección del túnel que se trató con Vancomicina y Gentamicina, observándose una buena evolución, aunque la zona que rodeaba el OSC comenzó a presentar enrojecimiento, sequedad, descamación (Figura 1). Se mantuvo la zona hidratada durante la sesión, con crema con urea al 5\%, y al retirar la HD, practicamos la protección habitual del catéter cubriendo con un apósito el OSC e introduciendo las ramas en un apósito Oper cat ${ }^{\circledR}$, fijando a la piel.

Persistió la sequedad de la piel, en la zona, originándose ampollas que se rompían, evolucionando a costras e incrementándose la irritación. Para que estas heridas mejoraran se utilizaron varias estrategias como cambiar el tipo de apósito, evitar el contacto de la piel con el plástico que contenían los apósitos, variar la zona de plástico de los apósitos de fijación o utilizar una malla para fijar. Posteriormente, se curó con pomada con corticoides y se apreció una mejoría que persistía al suspender su aplicación. 


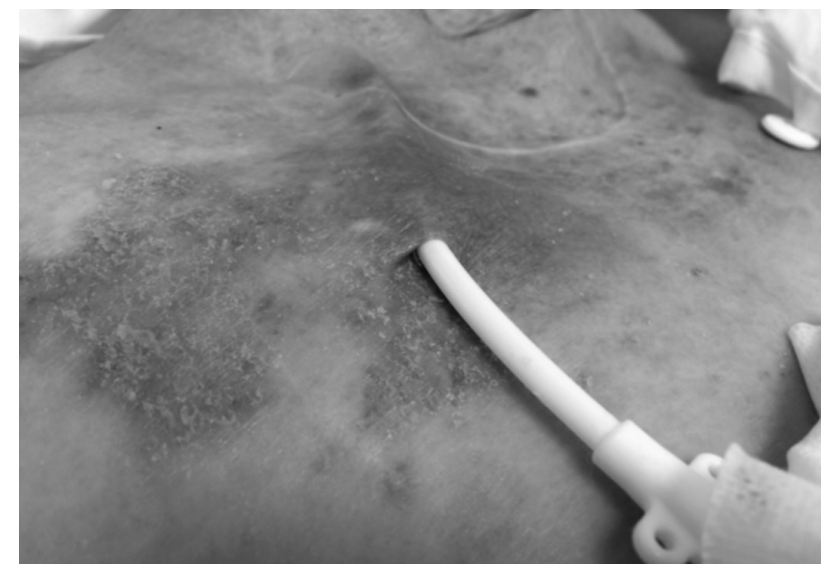

Figura 1. Aspecto de la piel ante la infección de la zona tunelizada.

- En enero de 2016 volvió a presentar una zona muy enrojecida a lo largo del túnel subcutáneo del catéter, que se trató con Vancomicina y Gentamicina, durante tres semanas. La piel de alrededor del OSC estaba seca y con eccemas produciendo a la paciente mucho prurito, por lo que se hidrató con aceite rosa mosqueta, siendo la evolución favorable.

- En febrero volvió a presentar una zona muy enrojecida a lo largo del trayecto del túnel. Se administró Vancomicina, se hidrató la piel con crema en las zonas secas y se aplicó Cavilon ${ }^{\circledR}$ (polímero que forma una barrera impermeable de larga duración) en las zonas sin lesiones para poder fijar el apósito. También, se aplicaron fomentos de cloruro sódico (CINa) al $20 \%$ en la zona durante unos $10-15$ minutos mientras realizábamos la sesión de HD.

Se produjo un leve sangrado por el OSC, por lo que se realizó un cultivo de esta zona que resultó ser positivo para SAMS y hemocultivos que fueron negativos. Observamos una mejoría en las ampollas, pero persistió el eritema en la zona del túnel por lo que se decidió administrar durante la sesión de HD de forma tópica una solución de 500 mg de Vancomicina disuelta en $10 \mathrm{ml}$ de suero en el trayecto tunelizado del CVCT. Para aplicarlo se utilizó un catéter muy fino (Abbocath ${ }^{\circledR} n^{\circ} 26$ ) que se introducía en el trayecto tunelizado del CVCT, así la solución de antibiótico impregnaba toda la zona del cuff (Figura 2). Tras cinco sesiones se observó que al presionar la zona cerca del OSC salía contenido sanguino-purulento, cuyo cultivo resultó positivo para SAMS, por lo que se decidió continuar con el tratamiento durante tres semanas más. Tras haber administrado la solución catorce veces remitió la infección, confirmándose por cultivos del exudado negativos. Continuamos aplicando los fomentos de $\mathrm{CINa} 20 \%$, en zonas cercanas al OSC durante varias sesiones para mejorar el aspecto de la piel y el prurito. Un año después, el CVCT se mantiene sin signos de infección y la piel presenta buen aspecto (Figura 3).

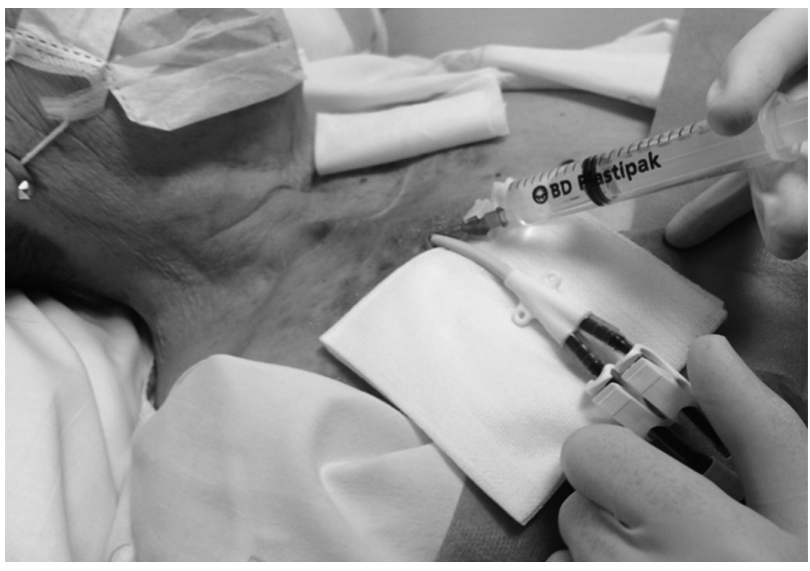

Figura 2. Aplicación del tratamiento intratúnel.

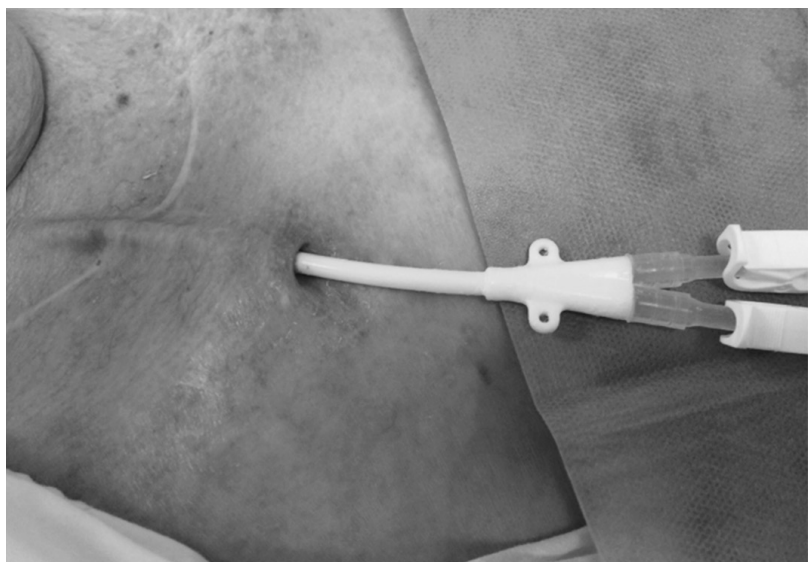

Figura 3. Aspecto de la zona ante la remisión de la infección.

\section{Discusión}

El estricto protocolo de asepsia utilizado en la unidad para manipular los CVCT ha permitido que las tasas de $B R C$ se mantengan en un nivel de excelencia $(<1 / 1000$ días de catéter $)^{5}$. Pese a seguir las mismas medidas esta paciente presentó varios episodios de infección del CVCT. Probablemente, estas infecciones se relacionaban con las alteraciones que sufría en la piel circundante al OSC, provocadas por las reacciones a los distintos tipos de apósitos. En los catéteres peritoneales, puede presentarse un problema similar y habitualmente se 
puede tratar mediante una extracción quirúrgica del cuff, estrategia que en ocasiones logra conservar el catéterb. Pero la exéresis de la zona con dacron no se puede llevar a cabo en los CVCT para HD porque cuando se produce una infección del túnel, es muy fácil que el propio cuff del catéter esté también colonizado por los gérmenes por lo que la única solución es la retirada de catéter. En el caso que describimos, y dada la dificultad de conseguir un nuevo acceso vascular, se intentó preservarlo y habida cuenta que los antibióticos administrados por vía venosa no surtían efecto, se decidió practicar una aplicación tópica para impregnar este cuff con antibiótico al que los microorganismos obtenidos en el cultivo eran sensibles. Cabe destacar que en nuestra unidad, este tratamiento tópico se había realizado en los catéteres de diálisis peritoneal, obteniendo buenos resultados, circunstancia que nos animó a utilizarlo en esta paciente.

En las guías de accesos vasculares, se contempla la retirada del catéter cuando persiste una infección del túnel subcutáneo ${ }^{1}$; los antibióticos por vía sistémica en muchas ocasiones son inefectivos y los tratamientos tópicos en el orificio de salida no siempre alcanzan el interior del túnel. En nuestro caso, la enorme dificultad que presentaba la obtención de un nuevo acceso vascular, y dada la situación estable de la paciente y la buena calidad de las sesiones de HD nos animó a persistir en nuestro intento de conservación del catéter. Aunque sea un único caso, quizás se deberían de tener en cuenta más alternativas de este tipo antes de proceder al recambio sistemático del catéter.

Recibido: 29 diciembre 2018

Revisado: 15 enero 2019

Modificado: 20 enero 2019

Aceptado: 2 febrero 2019

\section{Bibliografía}

1. Ibeas J, Roca-Tey R, Vallespín J, Moreno T, Moñux G, Martí-Monrós A et al. Guía Clínica Española del Acceso Vascular para Hemodiálisis. Enfermería Nefrol. 2018;21(Supl 1):S1-256.

2. Aguinaga A, Del Pozo JL. Infección asociada a catéter en hemodiálisis: diagnóstico, tratamiento y prevención. NefroPlus 2011;4(2):1-10.

3. Fariñas MC, García Palomo JD, Gutiérrez-Cuadra M. Infecciones asociadas a los catéteres utilizados para la hemodiálisis y la diálisis peritoneal. Enferm Infecc Microbiol Clin 2008;26(8):518-26.

4. Escalante E. Catéteres venosos centrales permanentes para hemodiálisis. En: González Álvarez MT, Martínez Cercós R. Manual de accesos vasculares para hemodiálisis. Barcelona: Marge Médica Books;2010. p. 193-206.

5. Beathard GA, Urbanes A. Infection associated with tunneled hemodialysis catheters. Semin Dial. $2008 ; 21(6): 528-38$.

6. Gómez Castilla C, Páez Antúnez MC, Ojeda Guerrero MA, Aresté Fonsalba N, Ramírez López MA, Fernández Gordillo D. La extrusión del dacrón subcutáneo como tratamiento de la infección crónica del orificio de salida del catéter de diálisis peritoneal. Rev Soc Esp Enferm Nefrol 2011;14(4):276-9.

Este artículo se distribuye bajo una Licencia Creative Commons Atribución-NoComercial 4.0 Internacional. https://creativecommons.org/licenses/by-nc/4.0/

\section{Open Access @) (1) ()}

